\title{
Ultrastructure of Rothia dentocariosa
}

\author{
By GENEVIVE D. ROTH \\ Department of Periodontics, University of Missouri-Kansas City School \\ of Dentistry, Kansas City, Missouri 64108, U.S.A. \\ R. G. GAR RISON \\ The Research Service, Veterans Administration Hospital, Kansas City, \\ and the Departments of Microbiology, University of Missouri-Kansas \\ City School of Dentistry and the University of Kansas School of \\ Medicine \\ AND KAREN S. BOYD \\ The Research Service, Veterans Administration Hospital, Kansas City
}

(Received I8 November 1975)

\begin{abstract}
SUMMARY
Rothia dentocariosa was seen as a typical prokaryotic cell, lacking nuclear envelope, mitochondria and a reticulum with ribosomes. The plasma membrane was located close to and parallel to the wall. The outer limits of the wall were associated with what may be capsular or slime material. Chain-like filaments of thick-walled coccoid cells underwent septation both transverse and parallel to the long axis of the chain. Side branching and terminal clavate forms were also present. These clavate forms may represent specialized cells during the life-cycle. Fragmentation of the chain resulted when the outer wall ruptured to release the coccoid bodies.
\end{abstract}

\section{IN TRODUCTION}

The genus Rothia, with its single species Rothia dentocariosa, was created as a new genus in the family Actinomycetaceae by Georg \& Brown (1967) to accommodate an organism previously known as Actinomyces dentocariosus (Onisi, 1949), Nocardia dentocariosus (Roth, I957), and N. salivae (Davis \& Freer, I960). Although the occurrence of $R$. dentocariosa as a resident of the human oral cavity is well established, it has been isolated from other clinical sources such as blood, spinal fluids, and abscesses (Brown, Georg \& Waters, 1969). The etiological relationship of $R$. dentocariosa to disease is not clear, although Roth \& Flanagan (1969) have demonstrated abscess formation in experimentally infected mice.

Georg (1974) describes $R$. dentocariosa as being a Gram-positive, non-acid fast, nonsporeforming, non-motile, highly pleomorphic organism. Growth at any given time may consist exclusively of coccoid, diphtheroid or filamentous forms or may be a mixture of any of these. The marked pleomorphic nature of $R$. dentocariosa, as observed by light microscopy, suggests that these different forms may represent various stages in the life-cycle of the organism. Thus the study of this organism by electron microscopy could be of value in establishing the inter-relationship of these forms. Such studies appear to be limited to that of Boyde \& Williams (197I), in which scanning electron microscopy was used to estimate the dimensions of individual cells and relative cell volumes of $R$. dentocariosa and other bacteria occurring in the mouth. Although no information is available on the fine structure 
of $R$. dentocariosa as observed by transmission electron microscopy, there is an increasing amount of information available on the fine structure of the Actinomycetales in general (reviewed by Williams, Sharples \& Bradshaw, 1973). A number of ultrastructural studies have been made on species of the genus Actinomyces (Overman \& Pine, 1963; Duda \& Slack, 1972; Girard \& Jacius, 1974). Slack \& Gerencser (1975) made a comprehensive study on the whole genus, but it contained no information on the ultrastructure of $R$. dentocariosa.

The present study was initiated to supplement the knowledge of the unusual morphology of $R$. dentocariosa, and to present a fine structural analysis of Rothia morphogenesis.

\section{METHODS}

Preparation of cultures. Rothia dentocariosa strains ATCCI4I89 and ATCCI7937 were obtained from the American Type Culture Collection. Unless otherwise indicated, cultures were grown aerobically for 24,48 , and $72 \mathrm{~h}$ in Difco Brain Heart Infusion (BHI) broth or on $2 \%(\mathrm{v} / \mathrm{v})$ sheep blood agar. In some instances, cultures were grown anaerobically on BHI agar plates (BBL GasPak System). All cultures were incubated at $37^{\circ} \mathrm{C}$. Cells were harvested in a Sorvall refrigerated centrifuge, washed in aqueous $\mathrm{NaCl}(0.9 \%, \mathrm{w} / \mathrm{v})$ and pelleted at $28700 \mathrm{~g}$.

Preparation for electron microscopy. Cells were fixed in pellet form at $4{ }^{\circ} \mathrm{C}$ with glutaraldehyde $(3 \%, \mathrm{v} / \mathrm{v})$ in $\mathrm{O} \cdot \mathrm{I} \mathrm{M}-\mathrm{s}$-collidine buffer, $\mathrm{pH} 6.8$, for $20 \mathrm{~h}$. After exhaustive washing in aqueous $\mathrm{NaCl}\left(0.9 \%\right.$ w/v), they were postfixed overnight at $4{ }^{\circ} \mathrm{C}$ with osmium tetroxide $(\mathrm{I} \%, \mathrm{w} / \mathrm{v})$ in $0 \cdot \mathrm{I} \mathrm{M}-\mathrm{s}$-collidine buffer, $\mathrm{pH} 7 \% 4$. Other cells were fixed for $\mathrm{Ih}$ at $4{ }^{\circ} \mathrm{C}$ in a mixture containing acrolein ( $\mathrm{I} \%, \mathrm{v} / \mathrm{v})$, glutaraldehyde $(\mathrm{I} \%, \mathrm{v} / \mathrm{v})$, tris-( I-aziridinyl)phosphine oxide (TAPO; I \%, v/v), as described by Djaczenko \& Cassone (I97I). Before osmium fixation, portions of the glutaraldehyde and TAPO-fixed cells were stained for I h at $25{ }^{\circ} \mathrm{C}$ in the acidified dialysed iron solution described by Rinehart \& Abul-Haj (I95I). All cells were incubated with an aqueous solution of uranyl magnesium acetate $(3 \%, \mathrm{w} / \mathrm{v})$ after fixing in osmium. A third portion of cells was fixed for 10 min at $4{ }^{\circ} \mathrm{C}$ in potassium permanganate $(0.6 \%, \mathrm{w} / \mathrm{v})$ dissolved in aqueous $\mathrm{NaCl}(0.9 \%, \mathrm{w} / \mathrm{v})$.

After fixation, all specimens were embedded in Difco Noble agar $(2 \%, w / v)$ to facilitate handling. Small agar cubes containing the cells were dehydrated in a graded series of ethanol dilutions and embedded in Epon 8I 2. Sections were cut with a diamond knife on an LKB Ultrotome III and picked up on uncoated 300-mesh copper grids. They were stained for 5 min with Reynold's lead citrate followed by Io min with uranyl acetate $(3 \%, \mathrm{w} / \mathrm{v})$ in absolute ethanol. Specimens were examined with an Hitachi electron microscope (model HU-IIB-I) at $75 \mathrm{kV}$.

\section{RESULTS}

Figures I and 2 show longitudinal thin sections of TAPO-fixed cells of $R$. dentocariosa from 24 and $48 \mathrm{~h}$ broth cultures, respectively. The coccoid cell (Fig. I) was bound by a wall of about $50 \mathrm{~nm}$ in thickness. The outer surface of the wall was somewhat more electrondense and was finely roughened. The granular cytoplasm contained a lamellar mesosomelike structure in apparent association with early transverse septum formation. Mesosomes have been found in a wide variety of the Actinomycetales, and a close association between mesosomes and developing cross walls has been noted (Williams et al., 1973). The nuclear region was irregular in shape and appeared less electron-dense than the immediate surrounding cytoplasm. Coccoid cells were seen frequently after $24 \mathrm{~h}$ incubation, while after $48 \mathrm{~h}$ incubation, many filamentous forms were observed. Occasionally, filaments were 

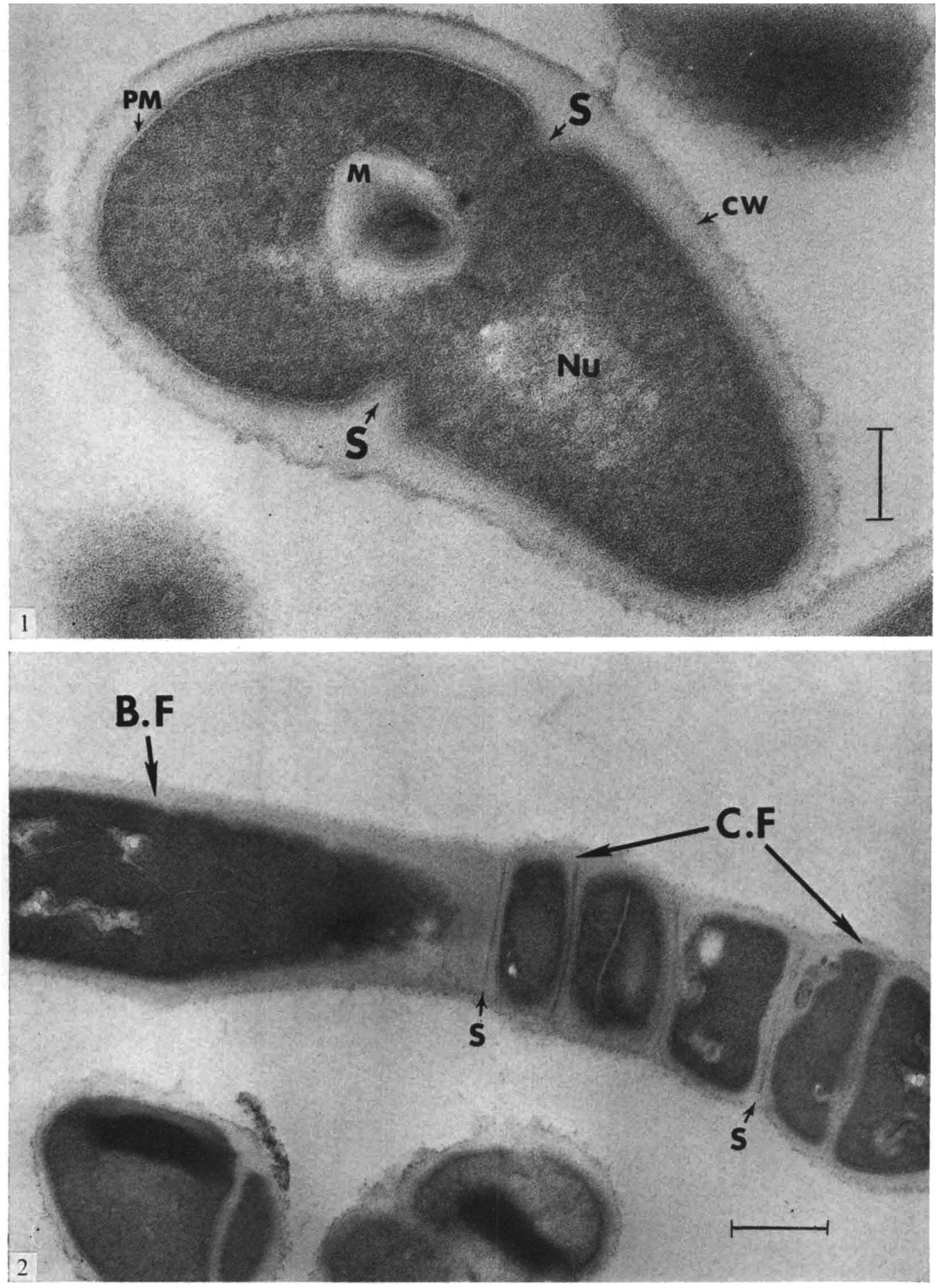

Fig. I. Section of a coccoid cell of $R$. dentocariosa $(24 \mathrm{~h})$. S, Transverse septal formation; CW, cell wall; PM, plasma membrane; M, mesosome; Nu, nuclear region. TAPO fixation. Bar marker represents $0 \cdot 10 \mu \mathrm{m}$.

Fig. 2. Section of a chain-like filament of $R$. dentocariosa ( $48 \mathrm{~h}$ ), showing both coccoid (C.F) and bacillary forms (B.F). S, Septum. TAPO fixation. Bar marker represents $0.25 \mu \mathrm{m}$. 

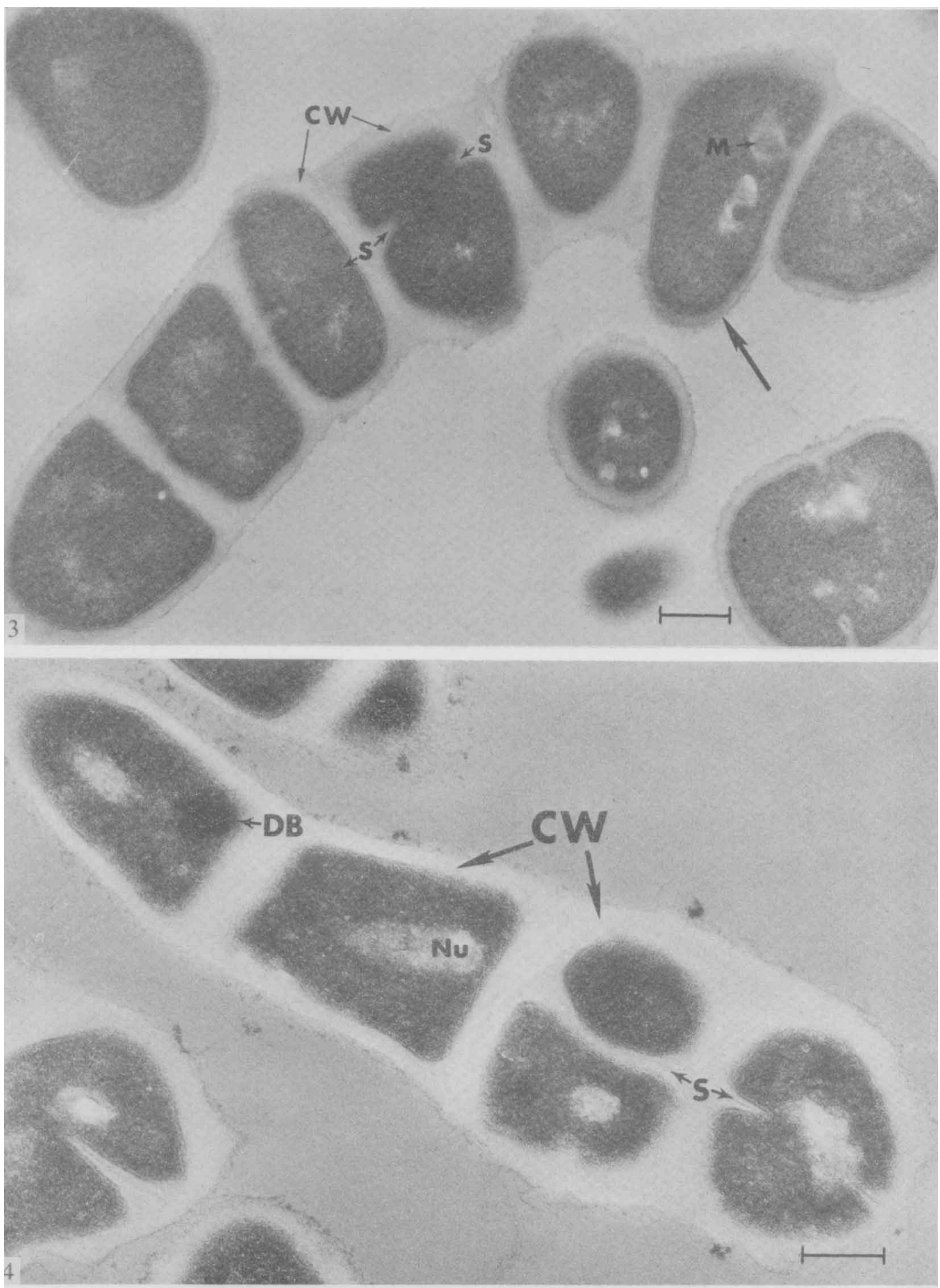

Fig. 3. Section of a chain-like filament of $R$. dentocariosa $(24 \mathrm{~h})$. Note the irregular shape of the individual cells, the elongation of the cell marked by the arrow, and the transverse septation (S) occurring parallel to the long axis of the chain. $\mathrm{CW}$, Cell wall; $\mathrm{M}$, mesosome. TAPO fixation. Bar marker represents $0.20 \mu \mathrm{m}$.

Fig. 4. Section of a chain-like filament of $R$. dentocariosa $(48 \mathrm{~h})$. Note the transverse septation (S) occurring parallel to the long axis. $\mathrm{CW}$, Cell wall; DB, dense body; $\mathrm{Nu}$, nuclear region. Permanganate fixation. Bar marker represents $0.20 \mu \mathrm{m}$. 

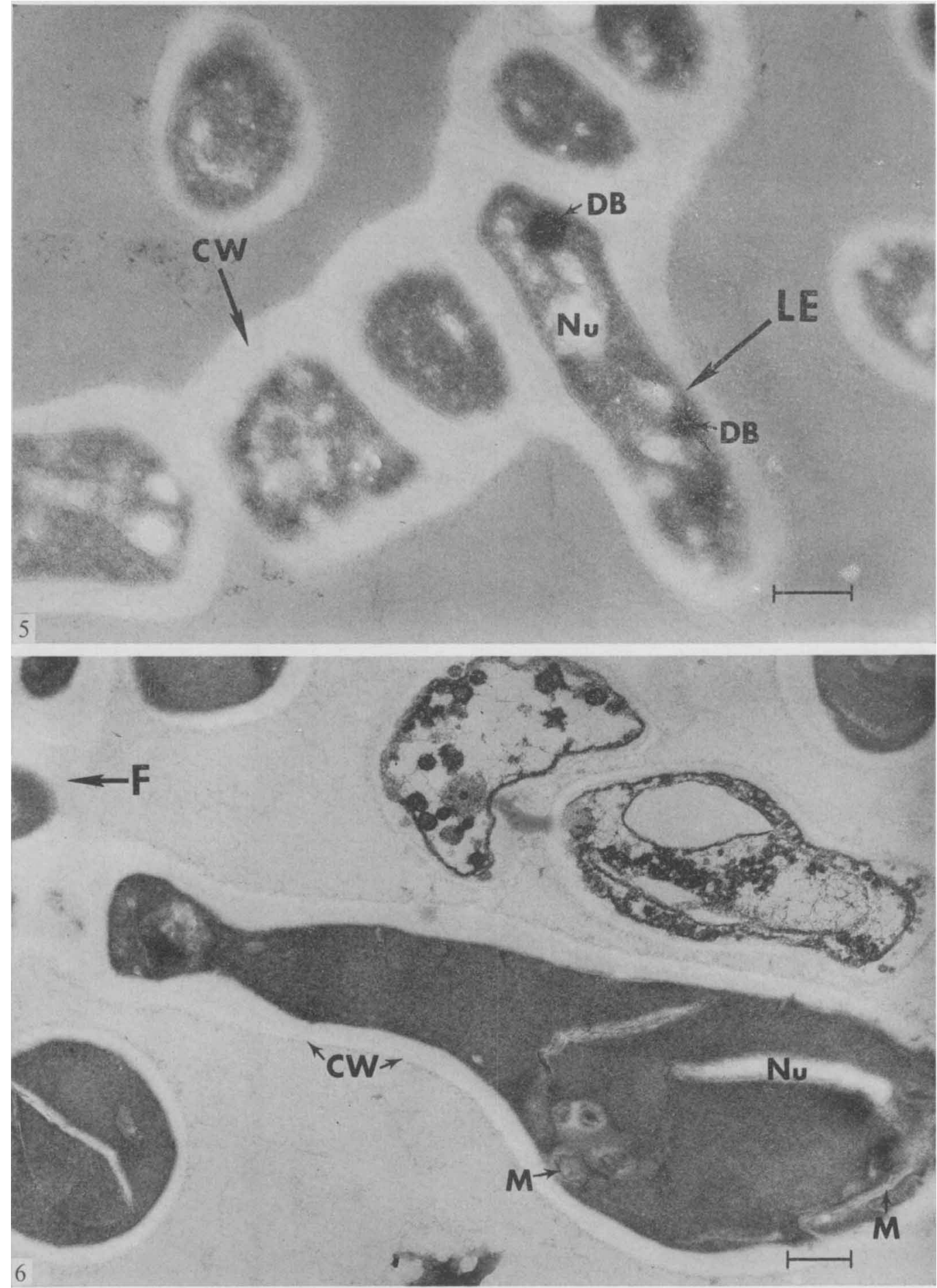

Fig. 5. Section of a chain-like filament of $R$. dentocariosa ( $48 \mathrm{~h}$ ). Note the lateral extension (LE). $\mathrm{CW}$, Cell wall; DB, dense body; Nu, nuclear region. Permanganate fixation. Bar marker represents $0.20 \mu \mathrm{m}$.

Fig. 6. Section of a clavate cell of $R$. dentocariosa $(72 \mathrm{~h})$. Note the origin of the clavate cell directly from the filament $(\mathrm{F})$. $\mathrm{CW}$, Cell wall; $\mathrm{M}$, mesosome; $\mathrm{Nu}$, nuclear region. Glutaraldehyde-osmium. Bar marker represents $0.25 \mu \mathrm{m}$. 

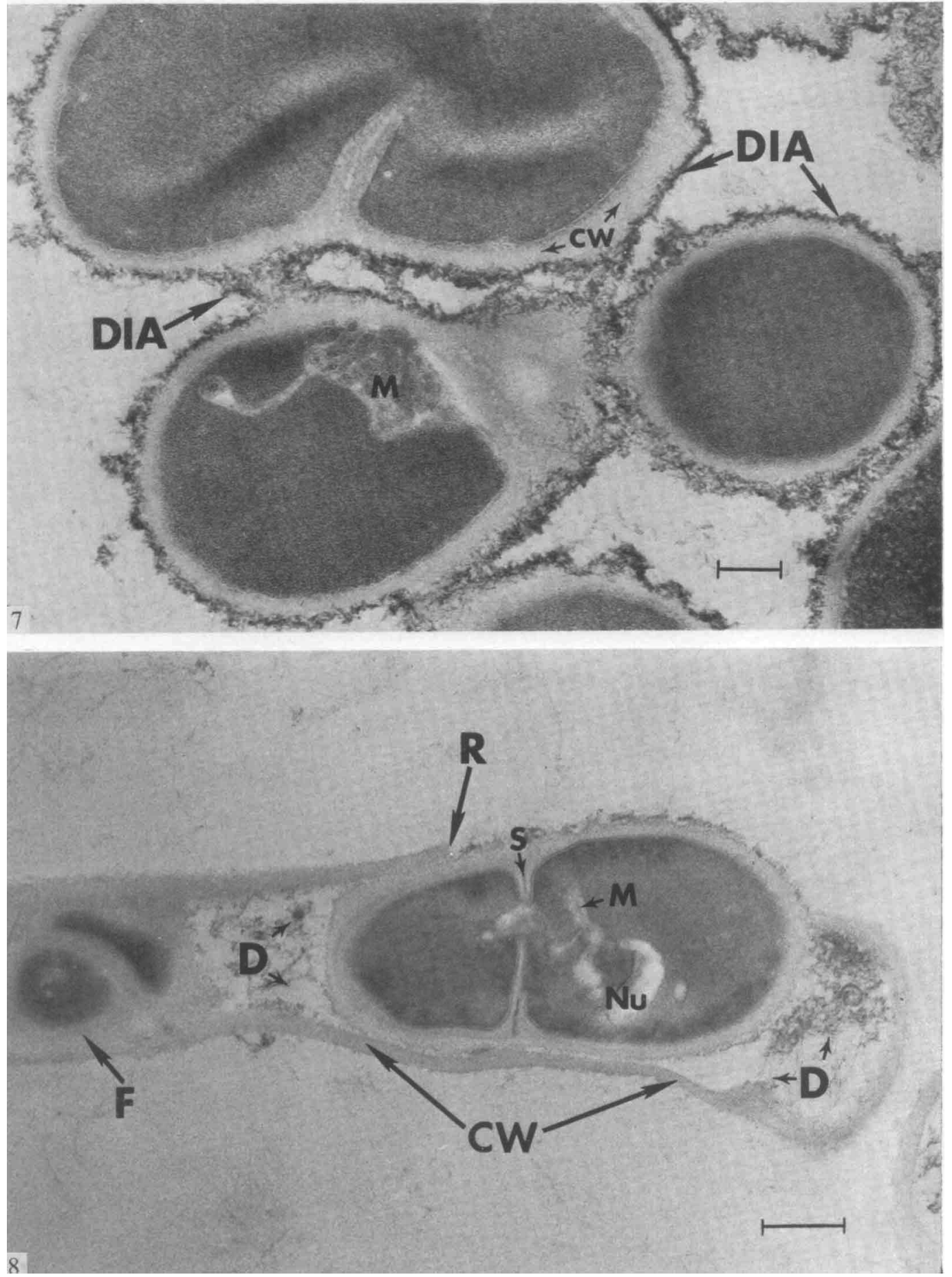

Fig. 7. Sections of coccoid cells of $R$. dentocariosa $(48 \mathrm{~h})$. Note the thin layer of electron-dense dialysed iron activity (DIA) at the outer limits of the cell wall (CW). M, Mesosome. Glutaraldehydedialysed iron-osmium. Bar marker represents $0.10 \mu \mathrm{m}$.

Fig. 8. Section of a chain-like filament of $R$. dentocariosa from a 7-day-old culture. Note the rupture (R) of the cell wall (CW) of the terminal portion of the filament (F), and the presence of a coccoid cell within the degenerate cytoplasm (D). Nu, Nuclear region; M, mesome; S, transverse septum. TAPO fixation. Bar marker represents $0.25 \mu \mathrm{m}$. 
composed of coccoid forms with a single bacillary form at the end of the filament (Fig. 2); however, electron microscopy indicated that the filaments were usually composed of several coccoid cells in a chain-like arrangement. Chains of bacillary cells were never seen, while single bacillary forms were only rarely observed. Cells comprising the chain-like filament varied somewhat in shape and size, perhaps as the result of the plane of the section, and were separated by thickened septal areas measuring $100 \mathrm{~nm}$ or more in thickness (Fig. 3). A characteristic feature was randomly occurring cells in the chain undergoing transverse septation parallel to the long axis of the filament and at the same time perpendicular to previously formed septa. Clear evidence of an ingrowth of the plasma membrane and wall material of adjacent septa is seen in Figs. 3 and 4 .

Fixation in permanganate resulted in poor differentiation of the wall and septal areas, although the fine detail of the cytoplasm and its content was well preserved (Figs. 4 and 5). The nuclear regions of the coccoid cells appeared irregular in shape and much less electrondense than the surrounding granular cytoplasm. Occasional electron-dense bodies of unknown identity were present in the cytoplasm. Septal formation parallel to the long axis of the filament was evident (Fig. 4) together with an apparent elongation or early lateral extension of one of the coccoid cells of the filament (Fig. 5). Although perhaps a result of the plane of the section, the absence of a parallel septum suggested that the elongating cell did not arise from one of a pair in the chain-like filament (see Fig. 4). A longitudinal section of a glutaraldehyde-osmium-fixed clavate cell from a $72 \mathrm{~h}$ broth culture (Fig. 6) may represent a mature form of the type of elongating cell shown in Fig. 5. The clavate cell was about $4 \mu \mathrm{m}$ in length, and its thickened wall measured up to $250 \mathrm{~nm}$ at the point of attachment to the filament. The finely granular cytoplasm of the clavate cell contained several small, delicate membraneous structures resembling mesosomes, and an elongate, less electron-dense area which may be the nuclear region.

Sections of coccoid cells fixed in glutaraldehyde-osmium and stained with the acidified dialysed iron solution of Rinehart \& Abul-Haj (195I) showed a thin, irregular layer of material binding dialysed iron over the entire outer surface of the cells (Fig. 7). Such iron capture reactivity was demonstrated with all cellular forms of $R$. dentocariosa, and suggests that staining with dialysed iron resulted in the conversion of a mucoid capsular or slime layer substance from an electron-transparent to an electron-dense material. No binding of dialysed iron was observed within the cell.

In the longitudinal section of a terminal portion of a TAPO-fixed filament from a 7 -dayold broth culture, a coccoid cell was located within the degenerate cytoplasm of the terminal cell and was partially surrounded by portions of the old wall (Fig. 8). The coccoid cell was undergoing transverse septation, with evidence of profiles of the nuclear region and what may be a mesosome associated with the developing septum. The wall of the degenerate terminal cell showed evidence of rupture resulting in the partial release of the septating coccoid cell. It is suggested that the filament terminus may be analogous to that shown in Fig. 2. However, since earlier stages in this development were not observed, the exact nature of the degenerate terminal cell is unknown.

\section{DISCUSSION}

In a detailed study of both stained and unstained mounts of $R$. dentocariosa, Roth \& Thurn (1962) reported that, on primary isolation, there was little evidence of elongation of the cells and that diplococcal forms were frequent. However, continued study of the cells at varying ages disclosed that diplococcal cells elongated to form filaments. Fragmentation 
of the cells was observed in the oldest area of the filament. Lateral branching occurred, with occasional club formation at the tip. The younger cells were uniformly Grampositive, but as the culture aged, the stain concentrated in bodies which formed within the filaments.

Our results may be interpreted somewhat differently from those obtained by light microscopy. Electron microscopy revealed that the membranes were limited to the plasma membrane and ramifications of it. The outer limits of the wall were found to be associated with a thin layer of what may be capsular or slime layer material. Capsular formation by $R$. dentocariosa has not been previously reported. This outer layer became evident on staining with dialysed iron and may be composed, in part, of an acid mucopolysaccharide. Extracellular substances at the outer surface of the wall have been reported for other organisms inhabiting dental plaque (Girard \& Jacius, 1974), and it was suggested that such material may enable these organisms to stay in contact with the tooth surface.

Electron microscopy of young cultures of $R$. dentocariosa grown on either agar or broth revealed numerous coccoid cells in various stages of transverse septation. Such cells might appear diplococcal when Gram stained. Within $48 \mathrm{~h}$, many chain-like filaments of thickwalled coccoid to slightly rectangular cells were observed. Since the cytoplasmic areas of these cells were small, retention of stains or vital dyes in the cytoplasm might give the impression that granules were located along the filament. Under the cultural conditions used, filaments of elongate or bacillary cells were not observed. However, bacillary to clavate forms occurred terminally on the chain-like filament of coccoid cells or as short lateral branches. The observation of coccoid cells within the chain undergoing septation parallel to the long axis of the filament has not been reported previously in the Actinomycetaceae. Although septation perpendicular to previously formed septa of the chain might provide a mechanism for lateral branch formation, no clear evidence of this was seen. In an ultrastructural study of several species of Actinomyces, Duda \& Slack (1972) found that chain growth of divided, unseparated cells, with branching and formation of cell clusters, was a consistent feature. Branching occurred by budding of a central cell in a chain with subsequent lateral outgrowth of the budding cell. This then divided with the formation of another chain perpendicular to the direction of growth of the parent cell that gave rise to a cluster. The septa were not always at right angles to the longitudinal axis of the cell and completed septa were often curved. Thus, in some respects, chain formation and branching by $R$. dentocariosa resembles that reported for species of Actinomyces. Little difference in morphology of $R$. dentocariosa was noted between cells grown anaerobically and those grown aerobically.

The bacillary and perhaps the clavate cells which arose from the chain-like filament of coccoid cells may have some specialized function in the life cycle of $R$. dentocariosa. The coccoid cells which arose within degenerating terminal portions of the filaments appeared to be ultrastructurally identical to those characteristically found in young cultures. This process is regarded as being identical to what Roth \& Thurn (1962) described as fragmentation. However, further studies are necessary to define clearly the nature of the parent cell, and the sequential steps involved in the development of these newly forming coccoid cells within the chain-like filaments of $R$. dentocariosa.

This study was supported by VA project no. 3046-o I administered by R. G. Garrison. 


\section{REFERENCES}

Boyde, A. \& Williams, R. A. D. (I971). Estimation of the volumes of bacterial cells by scanning electron microscopy. Archives of Oral Biology 16, 259-267.

Brown, J. M., GeorG, L. K. \& WAters, L. C. (1969). Laboratory identification of Rothia dentocariosa and its occurrence in human clinical materials. Applied Microbiology 17, I 50-1 56.

Davis, G. H. G. \& Freer, J. H. (I960). Studies upon an oral aerobic actinomycete. Journal of General Microbiology 23, 163-178.

Djaczenko, W. \& CASsone, A. (1971). Visualization of new ultrastructural components in the cell wall of Candida albicans with fixatives containing TAPO. Journal of Cell Biology 52, 186-190.

Duda, J. J. \& Slack, J. M. (1972). Ultrastructural studies on the genus Actinomyces. Journal of General Microbiology 71, 63-68.

Georg, L. K. (1974). Genus V. Rothia. In Bergey's Manual of Determinative Bacteriology, 8th edn, pp. 67968I. Edited by R. E. Buchanan and N. E. Gibbons. Baltimore: Williams and Wilkins.

GeorG, L. K. \& Brown, J. M. (1967). Rothia, gen. nov., and aerobic genus of the family Actinomycetaceae. International Journal of Systematic Bacteriology 17, 79-88.

GiraRd, A. E. \& JACIUS, B. H. (1974). Ultrastructure of Actinomyces viscosus and Actinomyces naeslundii. Archives of Oral Biology 19, 7I-79.

ONISI, M. (1949). Study on the Actinomyces isolated from the deeper layers of carious dentine. Shikagaku Zasshi 6, 273-282.

OVERMAN, J. R. \& Pine, L. (1963). Electron microscopy of cytoplasmic structures in facultative and anaerobic Actinomyces. Journal of Bacteriology 86, 656-665.

Rinehart, J. F. \& AbUl-HaJ, S. K. (I95I). An improved method for histologic demonstration of acid mucopolysaccharides in tissues. Archives of Pathology 52, I 89-194.

Rотн, G. D. ( 1 957). Proteolytic organisms of the carious lesion. Oral Surgery, Oral Medicine, Oral Pathology I0, I I05-III7.

Roth, G. D. \& Flanagan, V. (1969). The pathogenicity of Rothia dentocariosa inoculated into mice. Journal of Dental Research 48, 957-958.

Roth, G. D. \& Thurn, A. N. (1962). Continued study of oral Nocardia. Journal of Dental Research 4r, I $279-I 292$.

Slack, J. M. \& Gerencser, M. A. (1975). Actinomyces, Filamentous Bacteria: Biology and Pathogenicity. Minneapolis: Burgess Publishing Company.

Williams, S. T., Shar Ples, G. P. \& Bradshaw, R. M. (1973). The fine structure of the Actinomycetales. In Actinomycetales: Characteristics and Practical Importance, pp. I13-130. Edited by G. Sykes and F. A. Skinner. London and New York: Academic. 